\title{
Characterization of cotton ARF factors and the role of GhARF2b in fiber development
}

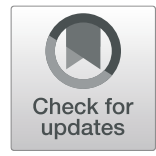

\author{
Xiufang Zhang ${ }^{1}$, Junfeng Cao ${ }^{1,2,3}$, Chaochen Huang ${ }^{1,4}$, Zishou Zheng ${ }^{1,3}$, Xia Liu ${ }^{5}$, Xiaoxia Shangguan , \\ Lingjian Wang ${ }^{1}$, Yugao Zhang ${ }^{5}$ and Zhiwen Chen ${ }^{1,6^{*}}$ (i)
}

\begin{abstract}
Background: Cotton fiber is a model system for studying plant cell development. At present, the functions of many transcription factors in cotton fiber development have been elucidated, however, the roles of auxin response factor (ARF) genes in cotton fiber development need be further explored.

Results: Here, we identify auxin response factor (ARF) genes in three cotton species: the tetraploid upland cotton G. hirsutum, which has 73 ARF genes, and its putative extent parental diploids G. arboreum and G. raimondii, which have 36 and 35 ARFs, respectively. Ka and Ks analyses revealed that in G. hirsutum ARF genes have undergone asymmetric evolution in the two subgenomes. The cotton ARFs can be classified into four phylogenetic clades and are actively expressed in young tissues. We demonstrate that GhARF2b, a homolog of the Arabidopsis AtARF2, was preferentially expressed in developing ovules and fibers. Overexpression of GhARF2b by a fiber specific promoter inhibited fiber cell elongation but promoted initiation and, conversely, its downregulation by RNAi resulted in fewer but longer fiber. We show that GhARF2b directly interacts with GhHOX3 and represses the transcriptional activity of GhHOX3 on target genes.
\end{abstract}

Conclusion: Our results uncover an important role of the ARF factor in modulating cotton fiber development at the early stage.

Keywords: Cotton, GhARF2b, Fiber elongation, Fiber initiation

\section{Background}

Cotton is the most important natural and renewable material for the textile industry in the world [1]. The primary cultivated species upland cotton (G. hirsutum L.) is grown in over 80 countries and accounts for more than $90 \%$ of global cotton fiber output. Cotton fibers are unusually long, single-celled epidermal seed trichomes and a model for plant cell growth research [2]. Fiber development can be divided into four overlapping stages:

\footnotetext{
* Correspondence: b1301031@cau.edu.cn

${ }^{1}$ National Key Laboratory of Plant Molecular Genetics and National Center for Plant Gene Research, Institute of Plant Physiology and Ecology/CAS Center for Excellence in Molecular Plant Sciences, Chinese Academy of Sciences, Shanghai 200032, China

${ }^{6}$ Institute of Carbon Materials Science, Shanxi Datong University, Datong 037009, China

Full list of author information is available at the end of the article
}

initiation, elongation, secondary cell wall biosynthesis and maturation [3]. The fiber length and density are both key traits that determine cotton quality and yield.

The study of cotton fiber development regulation provides not only valuable knowledge to understanding plant cell growth and cell wall biosynthesis, but also candidate genes for cotton molecular breeding [4]. To date a number of genes that function in cotton fiber cells have been identified, including homeodomain transcription factor GaHOX1, GhHOX3 and GhHD1 [5-7], bHLH transcription factor GhPRE1 [8], KNOX transcription factor knl1 [9], the sterol carrier gene [10], MYB transcription factors GhMYB25, GhMYB25-like, GhMML3 and GhMML4 [11-14], NAC transcription factor fsn1 [15], transcription factor WLIM1a gene [16], sucrose synthase gene [17], cotton actin1 gene [18],

(c) The Author(s). 2021 Open Access This article is licensed under a Creative Commons Attribution 4.0 International License, which permits use, sharing, adaptation, distribution and reproduction in any medium or format, as long as you give appropriate credit to the original author(s) and the source, provide a link to the Creative Commons licence, and indicate if changes were made. The images or other third party material in this article are included in the article's Creative Commons licence, unless indicated otherwise in a credit line to the material. If material is not included in the article's Creative Commons licence and your intended use is not permitted by statutory regulation or exceeds the permitted use, you will need to obtain permission directly from the copyright holder. To view a copy of this licence, visit http://creativecommons.org/licenses/by/4.0/ The Creative Commons Public Domain Dedication waiver (http://creativecommons.org/publicdomain/zero/1.0/) applies to the data made available in this article, unless otherwise stated in a credit line to the data. 
cotton BURP domain protein GhRDL1 [19], ethylene pathway related genes [20], fasciclin-like arabinogalactan protein, Ghfla1 [21], and TCP transcription factor GhTCP4 [22] etc. Among recent progresses are the characterizations of transcription factors which regulate the major events of cotton fiber development, such as MYBs and HD-ZIP IVs involved in cotton fiber initiation and elongation, as well as a number of other types of factors. The MIXTA type MYB transcription factors (GhMYB25, GhMYB25-like and GhMML4_D12) are master regulators of cotton fiber initiation [11, 13, 14] and lint fiber development [12], whereas the HD-ZIP IV transcription factor GhHOX3 plays a pivotal role in controlling fiber elongation [5], whose activity is regulated by the phytohormone gibberellin. In addition, NAC (GhFSN1) and TCP4 transcription factors positively regulates secondary cell wall biosynthesis $[15,22]$. However, cotton fiber growth and development are complex processes involving cell differentiation, cell skeleton orientation growth, cell wall synthesis, and so on [23]. Currently the picture of the regulation network of cotton fiber is far from complete.

Auxin response factors (ARFs), a group of plant transcription factors, are composed of a conserved Nterminal DNA binding domain (DBD), a most case conserved C-terminal dimerization domain (CTD) and a non-conserved middle region (MR) [24]. The MR region has been proposed to function as a repression or an activation domain [25]. Arabidopsis thaliana contains 23 ARF genes and Oryza sativa has 25 [26, 27]. It has been reported that ARF2 negatively modulates plant growth in A. thaliana [26, 28-30] and tomato [31], yet functions of transcription factors can vary with tissues and more diversified in polyploid species, to date the role ARF2 in cotton fiber cells has not been explored.

In this study, we conducted a genome-wide analysis ARF genes in three cotton species (G. hirsutum, G. arboreum and G. raimondii), and classified them into four clades. In G. hirsutum most $A R F$ genes were expressed in multiple cotton tissues, among which GhARF2 $b$ exhibited a preferential expression in developing cotton fiber cells, and it negatively affects cotton fiber elongation but plays a role in promoting fiber initiation.

\section{Results}

ARF transcription factors in G. arboreum and G. hirsutum The genome sequences of G. raimondii and G. arboreum provide us data resources to conduct a genome-wide screen of the $A R F$ genes in the extent diploid progenitors of the allotetraploid G. hirsutum. In the previous studies, Sun et al., (2015) identified 35 ARF genes in G. raimondii [32]. To mine more ARF transcription factors in cottons the conserved domain (Pfam ID: PF06507) was used to hmmersearch against the G. arboreum and G. hirsutum genome databases, which resulted in 36 and 73 genes in G. arboreum and G. hirsutum genomes, respectively. The $36 \mathrm{G}$. arboreum ARF genes were designated GaARF1-GaARF20, and the $73 \mathrm{G}$. hirsutum ARF genes in $\mathrm{A}$ - and $\mathrm{D}$-subgenomes were designated as GhARF1A/D-GhARF21A/D (Table 1). As those of Arabidopsis, cotton ARF proteins are composed of three domain regions, including DBD (DNA-binding Domain), MI (Middle Region) and CTD (C-terminal Domain) (Additional file 1: Figure S1).

\section{Phylogenetic analysis of Gossypium ARF proteins}

To illustrate the evolutionary relationships among the cotton ARFs, a phylogenetic tree was constructed using the protein sequences of 144 cotton ARFs, which were clustered into four clades (I-IV). The highest number of Gossypium ARFs are found in clade III and I, followed by clade IV and II (Fig. 1).

Overall, the expected diploid-polyploid topology is reflected in the tree for each set of orthologous/homoeologous genes, indicating general preservation during divergence of diploids and through the polyploid formation. We found that the number of ARF genes in G. hirsutum are approximately twice that in G. raimondii and G. arboreum, with one $\mathrm{A}_{\mathrm{t}}$ or $\mathrm{D}_{\mathrm{t}}$ homoeologous copy corresponding to one ortholog in each of the diploid cottons. Further, as shown in Fig. 1, the orthologous paired genes of the A genome (G. arboreum) and $A_{t}$ sub-genome, or from the D genome (G. raimondii) and $D_{t}$ sub-genome, tend to be clustered together and share a sister relationship.

\section{Divergence of ARF genes in allotetraploid G. hirsutum and its diploid progenitors}

The ARF genes in the two diploid species were then compared with $G$. hirsutum $\mathrm{A}_{\mathrm{t}^{-}}$and $\mathrm{D}_{\mathrm{t}^{-}}$-subgenome homoeologs (Table 1). To explore the evolutionary relationship and possible functional divergence of $A R F$ genes between the allotetraploid cotton and its extend diploid progenitors, the nonsynonymous substitution $(\mathrm{Ka})$ and synonymous substitution values $(K s)$ and the $K \mathrm{a} / K \mathrm{~s}$ ratios for each pair of the genes were calculated (Table 1). By comparing the $K a$ and $K s$ values of 66 orthologous gene sets between the allotetraploid and its diploid progenitor genomes, we found that the $K a$ and $K s$ values are higher in the $D_{t}$ subgenome than in the $A_{t}$ subgenome (Fig. 2). These results indicate that GhARF genes in the $D_{t}$ subgenome tend to have experienced faster sequence divergence than their $\mathrm{A}_{\mathrm{t}}$ counterparts, suggesting an inconsistent evolution of $A R F$ genes in the two subgenomes (Fig. 2).

In addition, the $K a / K s$ ratios of one $\mathrm{D}_{\mathrm{t}}$-subgenome genes $\left(G h A R F 3 b_{-} D\right)$ and five $\mathrm{A}_{\mathrm{t}}$-subgenome gene (GhARF2e_A, 
Table $1 \mathrm{Ka}, \mathrm{Ks}$ and $\mathrm{Ka} / \mathrm{Ks}$ analyses of GhARF genes compared with their corresponding progenitor homoeologs

\begin{tabular}{|c|c|c|c|c|c|c|c|c|}
\hline Locus Name & Gene Name & Chrom & Locus Name & Gene Name & Chrom & $\mathrm{Ka}$ & Ks & $\mathrm{Ka} / \mathrm{Ks}$ \\
\hline Gh_A10G1402 & GhARF1_A & A10 & Cotton_A_31395 & GaARF1 & CA_chr1 & 0.0147 & 0.0261 & 0.5632 \\
\hline Gh_D10G0803 & GhARF1_D & D10 & Gorai.011G091100.1 & GrARF1 & Chr11 & 0.0019 & 0.0108 & 0.1759 \\
\hline Gh_A07G0411 & GhARF2a_A & $\mathrm{A} 07$ & Cotton_A_03644 & GaARF2a & CA_chr1 & 0.0035 & 0.0068 & 0.5147 \\
\hline Gh_D07G0476 & GhARF2a_D & D07 & Gorai.001G054600.1 & GrARF2a & Chr1 & 0.0061 & 0.0169 & 0.3609 \\
\hline Gh_A11G0358 & GhARF2b_A & A11 & Cotton_A_01955 & GaARF2b & CA_chr6 & 0.0015 & 0.0151 & 0.0993 \\
\hline Gh_D11G0416 & GhARF2b_D & D11 & Gorai.007G044900.1 & GrARF2b & Chr7 & 0.0028 & 0.0045 & 0.6222 \\
\hline Gh_D12G1909 & GhARF2C_D & $\mathrm{D} 12$ & Gorai.008G210200.1 & GrARF2C & Chr8 & 0.0083 & 0.0263 & 0.3156 \\
\hline Gh_A11G1082 & GhARF2d_A & A11 & Cotton_A_08273 & GaARF2d & CA_chr4 & 0.0012 & 0.0021 & 0.5714 \\
\hline Gh_D11G1233 & GhARF2d_D & D11 & Gorai.007G131900.1 & GrARF2d & Chr7 & 0.0058 & 0.0181 & 0.3204 \\
\hline Gh_A08G0656 & GhARF2e_A & A08 & Cotton_A_22543 & GaARF2e & CA_chr10 & 0.0032 & 0.0000 & 2.0000 \\
\hline Gh_D08G0758 & GhARF2e_D & D08 & Gorai.004G085400.1 & GrARF2e & Chr4 & 0.0098 & 0.0213 & 0.4601 \\
\hline Gh_A10G0266 & GhARF3a_A & A10 & Cotton_A_03933 & GaARF3a & CA_chr9 & 0.0096 & 0.0167 & 0.5749 \\
\hline Gh_D10G0266 & GhARF3a_D & D10 & Gorai.011G030900.1 & GrARF3a & Chr11 & 0.0038 & 0.0125 & 0.3040 \\
\hline Gh_A06G2038 & GhARF3b_A & A06 & Cotton_A_40208 & GaARF3b & CA_chr8 & 0.0019 & 0.0060 & 0.3167 \\
\hline Gh_D06G1415 & GhARF3b_D & D06 & Gorai.010G157400.1 & GrARF3b & Chr10 & 0.0089 & 0.0077 & 1.1558 \\
\hline Gh_A05G1337 & GhARF3c_A & A05 & Cotton_A_11311 & GaARF3c & CA_chr10 & 0.0165 & 0.0140 & 1.1786 \\
\hline Gh_D05G1506 & GhARF3c_D & D05 & Gorai.009G166100.1 & GrARF3C & Chr9 & 0.0018 & 0.0076 & 0.2368 \\
\hline Gh_A09G0993 & GhARF4a_A & A09 & Cotton_A_01738 & GaARF4a & CA_chr11 & 0.0017 & 0.0116 & 0.1466 \\
\hline Gh_A05G3908 & GhARF4b_A & A05 & Cotton_A_11048 & GaARF4b & CA_chr10 & 0.0027 & 0.0018 & 1.5000 \\
\hline Gh_A01G0908 & GhARF5a_A & $\mathrm{A} 01$ & Cotton_A_27669 & GaARF5a & CA_chr13 & 0.0009 & 0.0110 & 0.0818 \\
\hline Gh_D01G0951 & GhARF5a_D & D01 & Gorai.002G124400.1 & GrARF5a & Chr2 & 0.0032 & 0.0094 & 0.3404 \\
\hline Gh_A05G1607 & GhARF5b_A & A05 & Cotton_A_16408 & GaARF5b & CA_chr8 & 0.0046 & 0.0079 & 0.5823 \\
\hline Gh_D05G1792 & GhARF5b_D & D05 & Gorai.009G196100.1 & GrARF5b & Chr9 & 0.0067 & 0.0172 & 0.3895 \\
\hline Gh_A10G0412 & GhARF6a_A & A10 & Cotton_A_02933 & GaARF6a & CA_chr9 & 0.0038 & 0.0159 & 0.2390 \\
\hline Gh_D10G0426 & GhARF6a_D & D10 & Gorai.011G048200.1 & GrARF6a & Chr11 & 0.0019 & 0.0047 & 0.4043 \\
\hline Gh_A05G1225 & GhARF6b_A & A05 & Cotton_A_26156 & GaARF6b & CA_chr10 & 0.0034 & 0.0095 & 0.3579 \\
\hline Gh_D05G3848 & GhARF6b_D & D05 & Gorai.009G152700.1 & GrARF6b & Chr9 & 0.0107 & 0.0205 & 0.5220 \\
\hline Gh_D07G1785 & GhARF8a_D & D07 & Gorai.001G204500.1 & GrARF8a & Chr1 & 0.0028 & 0.0091 & 0.3077 \\
\hline Gh_A12G0813 & GhARF8b_A & $\mathrm{A} 12$ & Cotton_A_35443 & GaARF8b & CA_chr6 & 0.0017 & 0.0054 & 0.3148 \\
\hline Gh_D12G0831 & GhARF8b_D & $\mathrm{D} 12$ & Gorai.008G097200.1 & GrARF8b & Chr8 & 0.0039 & 0.0049 & 0.7959 \\
\hline Gh_A12G0483 & GhARF8c_A & $\mathrm{A} 12$ & Cotton_A_21333 & GaARF8c & CA_chr6 & 0.0235 & 0.0303 & 0.7756 \\
\hline Gh_D12G0491 & GhARF8c_D & D12 & Gorai.008G054600.1 & GrARF8C & Chr8 & 0.0061 & 0.0167 & 0.3653 \\
\hline Gh_A09G0074 & GhARF8d_A & A09 & Cotton_A_14740 & GaARF8d & CA_chr11 & 0.0030 & 0.0131 & 0.2290 \\
\hline Gh_D09G0071 & GhARF8d_D & D09 & Gorai.006G008700.1 & GrARF8d & Chr6 & 0.0031 & 0.0150 & 0.2067 \\
\hline Gh_A11G0231 & GhARF9a_A & A11 & Cotton_A_18937 & GaARF9a & CA_chr10 & 0.0108 & 0.0301 & 0.3588 \\
\hline Gh_D11G0245 & GhARF9a_D & D11 & Gorai.007G026900.1 & GrARF9a & Chr7 & 0.0098 & 0.0198 & 0.4949 \\
\hline Gh_A02G0979 & GhARF9b_A & $\mathrm{A} 02$ & Cotton_A_36154 & GaARF9b & CA_chr7 & 0.0013 & 0.0044 & 0.2955 \\
\hline Gh_D03G0771 & GhARF9b_D & D03 & Gorai.003G078000.1 & GrARF9b & Chr3 & 0.0019 & 0.0064 & 0.2969 \\
\hline Gh_A03G0274 & GhARF10a_A & $\mathrm{A} 03$ & Cotton_A_04263 & GaARF10a & CA_chr7 & 0.0013 & 0.0062 & 0.2097 \\
\hline Gh_D03G1293 & GhARF10a_D & D03 & Gorai.003G142500.1 & GrARF10a & Chr3 & 0.0058 & 0.0171 & 0.3392 \\
\hline Gh_A05G0895 & GhARF10b_A & A05 & Cotton_A_07064 & GaARF10b & CA_chr10 & 0.0038 & 0.0102 & 0.3725 \\
\hline Gh_D05G0978 & GhARF10b_D & D05 & Gorai.009G107800.1 & GrARF10b & Chr9 & 0.0025 & 0.0185 & 0.1351 \\
\hline Gh_A07G1254 & GhARF11_A & $\mathrm{A} 07$ & Cotton_A_31049 & GaARF11 & CA_chr1 & 0.0044 & 0.0105 & 0.4190 \\
\hline Gh_A10G1836 & GhARF16a_A & A10 & Cotton_A_23397 & GaARF16a & CA_chr9 & 0.0019 & 0.0150 & 0.1267 \\
\hline
\end{tabular}


Table $1 \mathrm{Ka}, \mathrm{Ks}$ and $\mathrm{Ka} / \mathrm{Ks}$ analyses of GhARF genes compared with their corresponding progenitor homoeologs (Continued)

\begin{tabular}{|c|c|c|c|c|c|c|c|c|}
\hline Locus Name & Gene Name & Chrom & Locus Name & Gene Name & Chrom & $\mathrm{Ka}$ & Ks & $\mathrm{Ka} / \mathrm{Ks}$ \\
\hline Gh_D10G2093 & GhARF16a_D & D10 & Gorai.011G238900.1 & GrARF16a & Chr11 & 0.0063 & 0.0193 & 0.3264 \\
\hline Gh_A05G3576 & GhARF16b_A & A05 & Cotton_A_06107 & GaARF16b & CA_chr12 & 0.0097 & 0.0066 & 1.4697 \\
\hline Gh_D04G0030 & GhARF16b_D & D04 & Gorai.012G004800.1 & GrARF16b & Chr12 & 0.0051 & 0.0087 & 0.5862 \\
\hline Gh_A09G1401 & GhARF16c_A & A09 & Cotton_A_24047 & GaARF16c & CA_chr10 & 0.0031 & 0.0103 & 0.3010 \\
\hline Gh_D09G1405 & GhARF16c_D & D09 & Gorai.006G166400.1 & GrARF16c & Chr6 & 0.0025 & 0.0081 & 0.3086 \\
\hline Gh_A13G2013 & GhARF16d_A & A13 & Cotton_A_10518 & GaARF16d & CA_chr8 & 0.0080 & 0.0109 & 0.7339 \\
\hline Gh_D13G2411 & GhARF16d_D & D13 & Gorai.013G267100.1 & GrARF16d & Chr13 & 0.0041 & 0.0223 & 0.1839 \\
\hline Gh_A05G1991 & GhARF17a_A & A05 & Cotton_A_16138 & GaARF17a & CA_chr10 & 0.0030 & 0.0243 & 0.1235 \\
\hline Gh_D05G3805 & GhARF17a_D & D05 & Gorai.009G241900.1 & GrARF17a & Chr9 & 0.0015 & 0.0121 & 0.1240 \\
\hline Gh_A06G0332 & GhARF17b_A & A06 & Cotton_A_18446 & GaARF17b & CA_chr8 & 0.0030 & 0.0025 & 1.2000 \\
\hline Gh_D06G0360 & GhARF17b_D & D06 & Gorai.010G046000.1 & GrARF17b & Chr10 & 0.0076 & 0.0099 & 0.7677 \\
\hline Gh_A11G0886 & GhARF18a_A & A11 & Cotton_A_14407 & GaARF18a & CA_chr4 & 0.0041 & 0.0074 & 0.5541 \\
\hline Gh_D11G1034 & GhARF18a_D & D11 & Gorai.007G109500.1 & GrARF18a & Chr7 & 0.0057 & 0.0133 & 0.4286 \\
\hline Gh_A12G1016 & GhARF18b_A & $\mathrm{A} 12$ & Cotton_A_25871 & GaARF18b & CA_chr6 & 0.0045 & 0.0150 & 0.3000 \\
\hline Gh_D12G1134 & GhARF18b_D & $\mathrm{D} 12$ & Gorai.008G126200.1 & GrARF18b & Chr8 & 0.0026 & 0.0201 & 0.1294 \\
\hline Gh_A06G0710 & GhARF19.1a_A & A06 & Cotton_A_38575 & GaARF19.1a & CA_chr13 & 0.0048 & 0.0130 & 0.3692 \\
\hline Gh_D06G0818 & GhARF19.1a_D & D06 & Gorai.010G091300.1 & GrARF19.1a & Chr10 & 0.0293 & 0.0343 & 0.8542 \\
\hline Gh_A07G2353 & GhARF19.1b_A & $\mathrm{A} 07$ & Cotton_A_05677 & GaARF19.1b & CA_chr1 & 0.0042 & 0.0218 & 0.1927 \\
\hline Gh_D07G0132 & GhARF19.1b_D & D07 & Gorai.001G017000.1 & GrARF19.1b & Chr1 & 0.0032 & 0.0113 & 0.2832 \\
\hline Gh_A05G3541 & GhARF19.2_A & A05 & Cotton_A_06071 & GaARF19.2 & CA_chr12 & 0.0148 & 0.0254 & 0.5827 \\
\hline Gh_D04G0067 & GhARF19.2_D & D04 & Gorai.012G009000.1 & GrARF19.2 & Chr12 & 0.0039 & 0.0040 & 0.9750 \\
\hline Gh_A05G0264 & GhARF20_A & A05 & Cotton_A_27843 & GaARF20 & CA_chr9 & 0.0020 & 0.0121 & 0.1653 \\
\hline Gh_D08G1407 & GhARF21_D & D08 & Gorai.006G045300.1 & GrARF21 & Chr6 & 0.1826 & 0.2293 & 0.7963 \\
\hline
\end{tabular}

GhARF3c_A, GhARF4b_A, GhARF16b_A and GhARF17b_ $A$ ) are greater than 1 (Table 1), suggesting that these genes have under positive selections after divergence of G. hirsutum from diploid ancestors, and may have gained new functions.

\section{Expression analysis of GhARF genes in different cotton tissues}

The expression profile of a gene family can provide valuable clues to possible functions of each genes. Analysis of 73 GhARF genes showed that most genes have different spatial expression patterns. For instance, GhARF1, $G h A R F 2 a, G h A R F 2 b$ and $G h A R F 2 c$ were expressed in all the tissues of cotton examined (Additional file 2: Figure S2), whereas GhARF3a and GhARF3c were expressed preferentially in the pistils and ovules. Compared to GhARF5b, GhARF5a showed higher expressions in the root, pistil and ovule organs. Transcripts of GhARF3c and GhARF4a, GhARF9a and GhARF9b were most abundant in stem and root, respectively. Over half of GhARF genes showed a relatively high level of transcript accumulation in leaf. Notably, there are more than 10 genes (including GhARF1, GhARF2a, GhARF2b, GhARF8a, GhARF9a, GhARF10b, GhARF11, GhARF16a, GhARF18 and GhARF19) that were highly expressed in cotton fiber cells at the fast elongation stage ( $5 \mathrm{dpa})$.

Among them, GhARF2 genes showed the highest expression in fiber ( $5 \mathrm{dpa}$ ) and were located in the Clade I of phylogenetic tree (Fig. 1), suggesting that they may function in cotton fiber development. Previous studies have demonstrated that ARF2 plays a role in transcriptional regulation in auxin-mediated cell division [30], leaf longevity [33], response to stress [34], regulation of fruit ripening [31] and so on. As GhARF2s shown pleiotropic effects on plant development [35], we decided to identify the major GhARF2s in regulation of cotton fiber elongation in subsequent experiments.

\section{GhARF2 had a high expression pattern during fiber elongation process}

There are nine ARF2 genes in G. hirsutum (GhARF2c_ At not annotated), we first examined their expression profiles in different tissues in cotton (Fig. 3). Based on the RNA-seq data (Zhang et al., 2015), GhARF2a, 


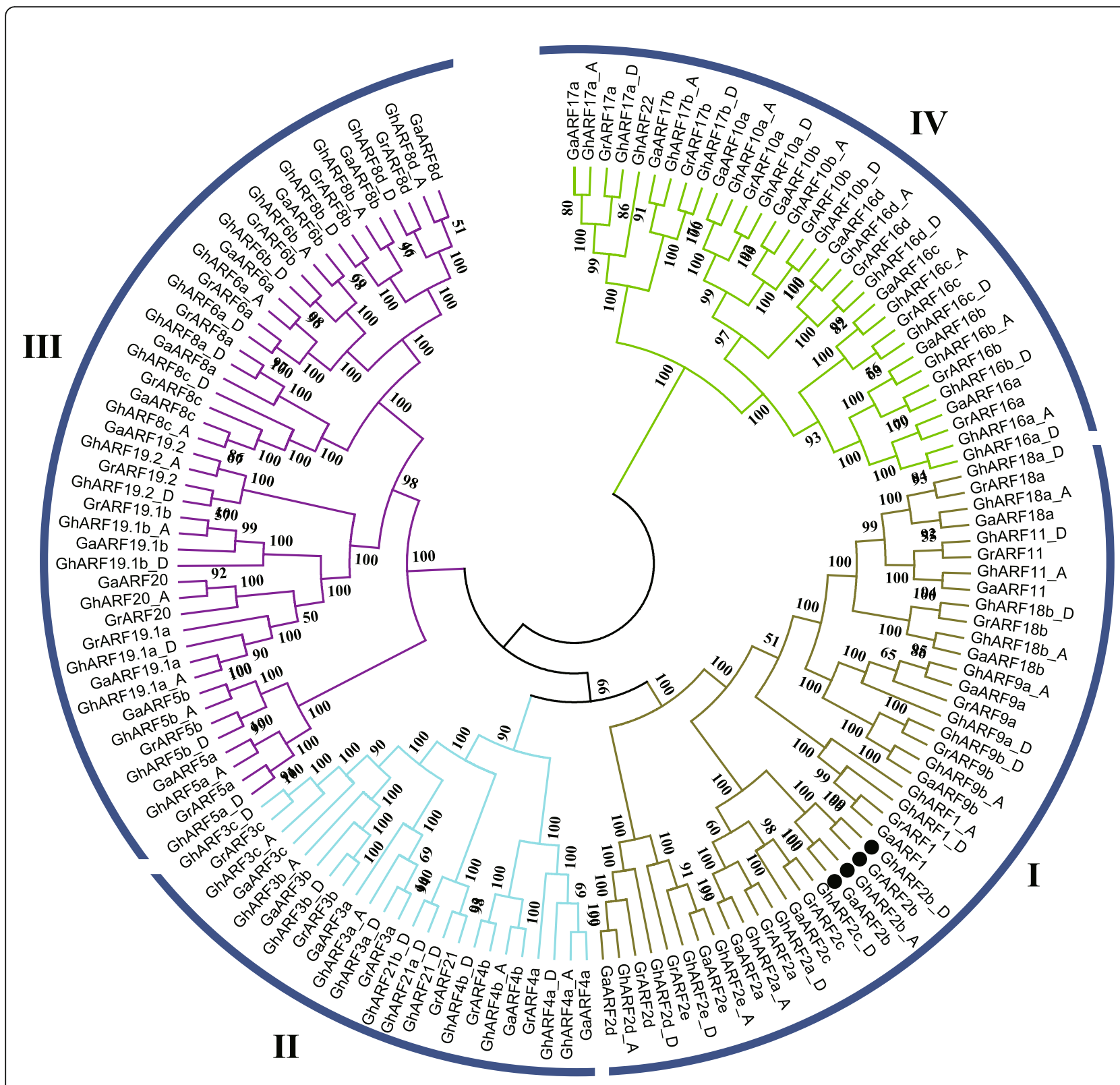

Fig. 1 Phylogenetic trees of Gossypium ARFs family. 144 Gossypium ARFs were divided into four clades. Black dots represent the ARF2b genes in three Gossypium species

GhARF $2 b$ and $G h A R F 2 c$ genes had higher expression levels in various tissues than GhARF2d or GhARF2e (Fig. $3 \mathrm{a})$. Among them, in $5 \mathrm{dpa}$ fiber, the expressions of GhARF2b were 1.1-37 folds to other four GhARF2 genes. Whereas in ovule (0dpa), GhARF2b showed 1.215 folds higher expressions than others. Thus, the transcripts of GhARF2b homoeologs (GhARF2b_At and GhARF2b_Dt) were enriched and abundant in cotton fiber and ovule cells (Fig. 3a). Subsequent quantitative RT-PCR (qRT-PCR) confirmed the expression pattern, and GhARF2 $b$ showed 3.6-9 folds higher expressions in fiber (3dpa) or ovule (0dpa) than other tissues (Fig. 3b). The highly up-regulated expression in fiber cell suggested that GhARF2b has been recruited to act primarily in cotton fiber.

\section{GhARF2b overexpression represses cotton fiber elongation}

To test the function of GhARF2b, we constructed the vectors to over-express and down-regulate GhARF2b_Dt in $G$. hirsutum by using the fiber-specific GhRDL1 promoter $[8,19,36]$. The expression levels of GhARF2b in 


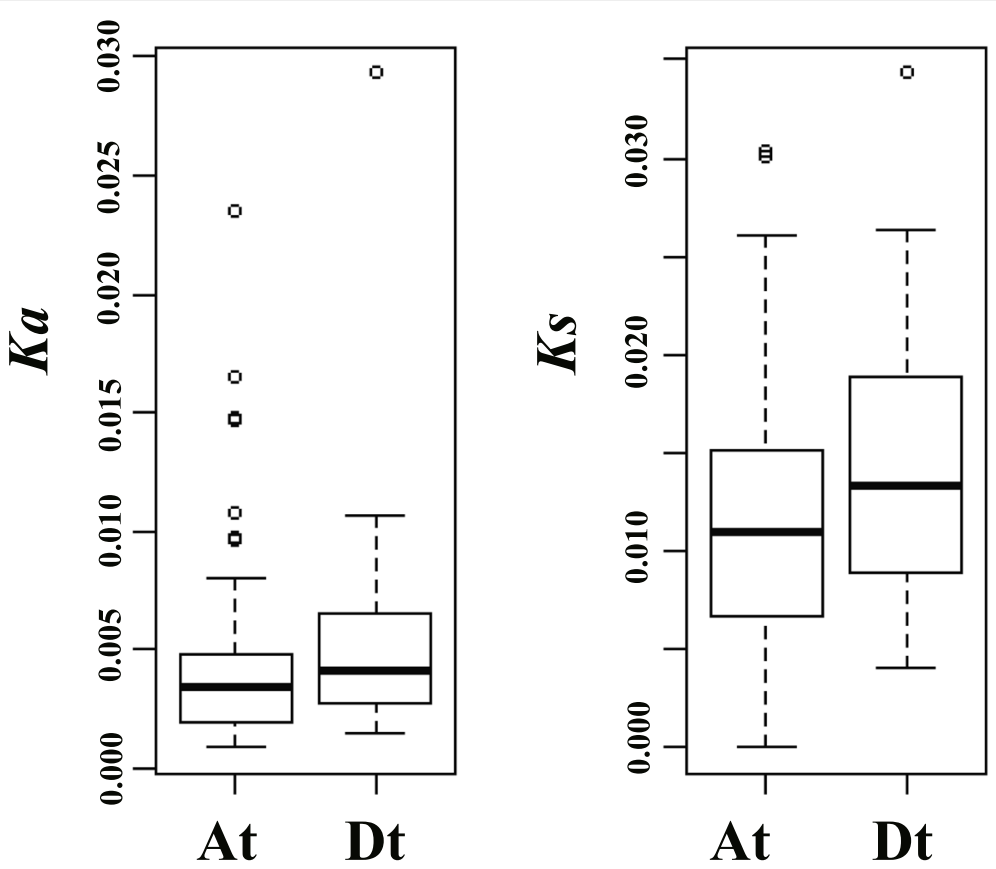

Fig. 2 Distribution of Ka and Ks values of ARF genes between the A and D subgenomes versus their corresponding diploid progenitor homoeologs

transgenic cotton were clearly elevated in the overexpression lines according to qRT-PCR analysis; for example, the GhARF2b transcript abundance was about two-fold higher in the OE-3 than in the wild-type cotton fiber cells (Fig. 4a). However, GhARF2b did not stimulate fiber cell elongation, rather, it resulted in shorter fiber (Fig. 4b, c).

On the contrary, suppressing GhARF2b expression by RNAi resulted in longer fibers (Fig. 5a, b). The expression levels of GhARF2b in RNAi cottons in the RNAi lines were about $3 \sim 5$-fold down-regulated in cotton fiber of 0DPA, 6DPA and 12DPA (Fig. 5c-e). Together, these data suggest that GhARF2b acted as a negative regulator of fiber cell elongation, at least when its expression exceeded the threshold. Alternatively, it may function in other aspects of cotton fiber development.

\section{GhARF2b interacted with GhHOX3}

The homeodomain-leucine zipper (HD-ZIP) transcription factor, GhHOX3, plays a determinant role in controlling cotton fiber elongation [5]. We used the yeast two-hybrid system $(\mathrm{Y} 2 \mathrm{H})$ to screen a cotton fiber cDNA library for GhHOX3 interacting proteins. GhARF2 was among the top five interacting factors of the target proteins. In further yeast two-hybrid assays, GhARF2b and GhARF2b middle region strongly interacted with GhHOX3 (Fig. 6a, b). We also used bimolecular fluorescence complementation (BiFC) assays to confirm the interaction between GhARF2b and GhHOX3 (Fig. 6c).
The transcriptional activities of GhHOX3 target genes were repressed by GhARF2b protein interactions

Given the fact that GhARF2b represses cotton fiber elongation, we tested the two protein interactions would affect the transcriptional activation of GhHOX3 target genes. Two cell wall protein coding genes [19, 36], GhRDL1 and GhEXPA1, are direct targets of GhHOX3 in promoting the fiber elongation [5]. We used a dualluciferase assay system to study the effect of GhARF2b on activity of GhHOX3 protein (Fig. 7a). The level of the luciferase activity driven by GhRDL1 and GhEXPA1 promoters was significantly increased when GhHOX3 was expressed (Fig. 7b, c). In contrast, activation of GhHOX3 to GhRDL1 or GhEXPA1 promoters was significantly repressed by GhARF2b (Fig. 7b, c). These results further supported that interaction of GhARF2b with GhHOX3 results in a much lower activity of targets gene activation, thus cotton fiber elongation was disturbed.

GhARF2 $b$ overexpression enhances cotton fiber initiation Next, we examined the effects of GhARF2 $b$ up-regulation on cotton fiber initiation. The over-expression line OE-3 and RNAi line ds- 2 were selected for analyses. The SEM with $60 \times$ magnification of ovules of WT-R15, OE-3 and ds-2 collected at $-1,0,1$ DPA were observed (Fig. 8). The cotton fiber initiation of the -1-DPA ovules did not present differences among the three types of cottons, however, the 0- and 1-DPA ovules of OE-3 and ds-2 lines 

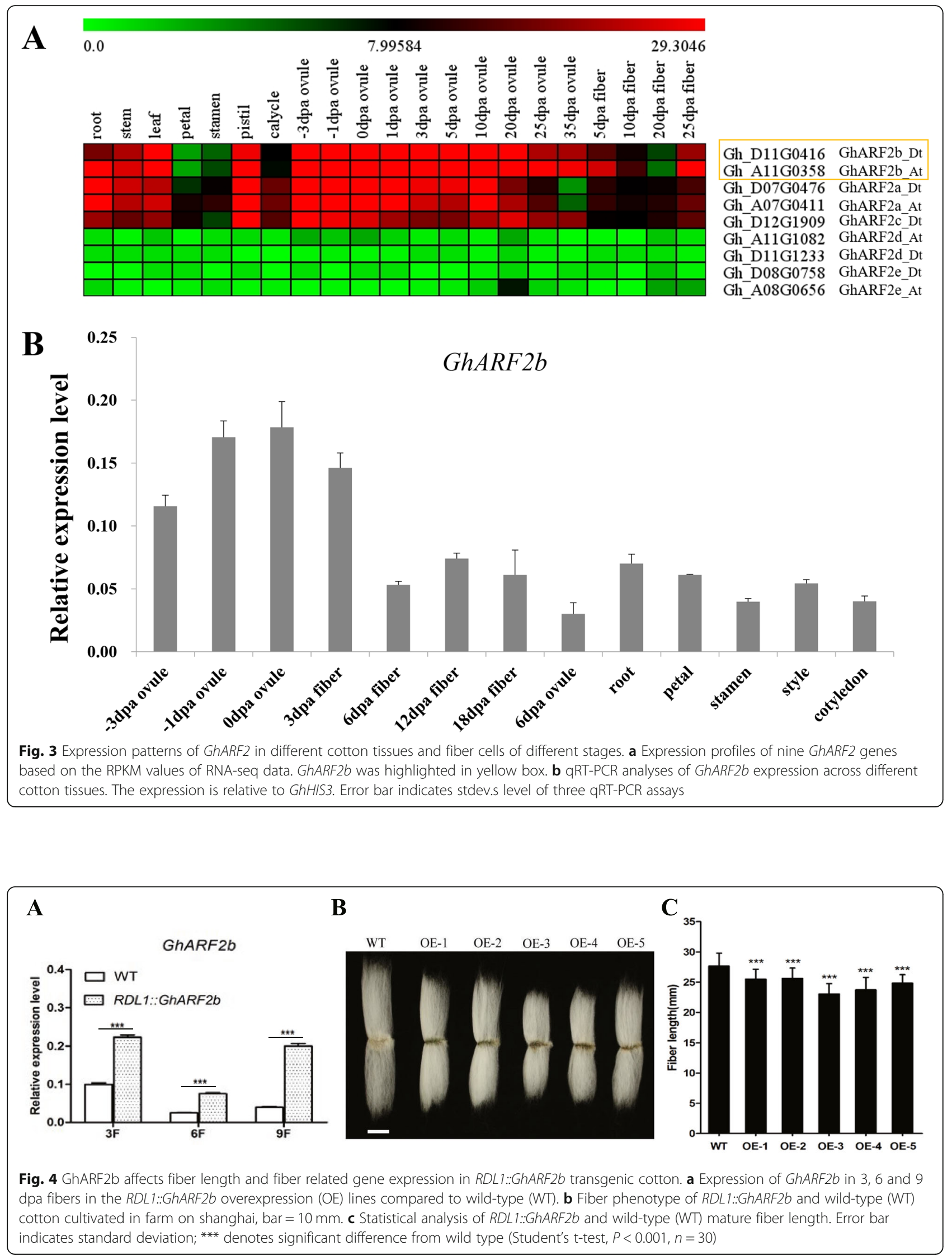


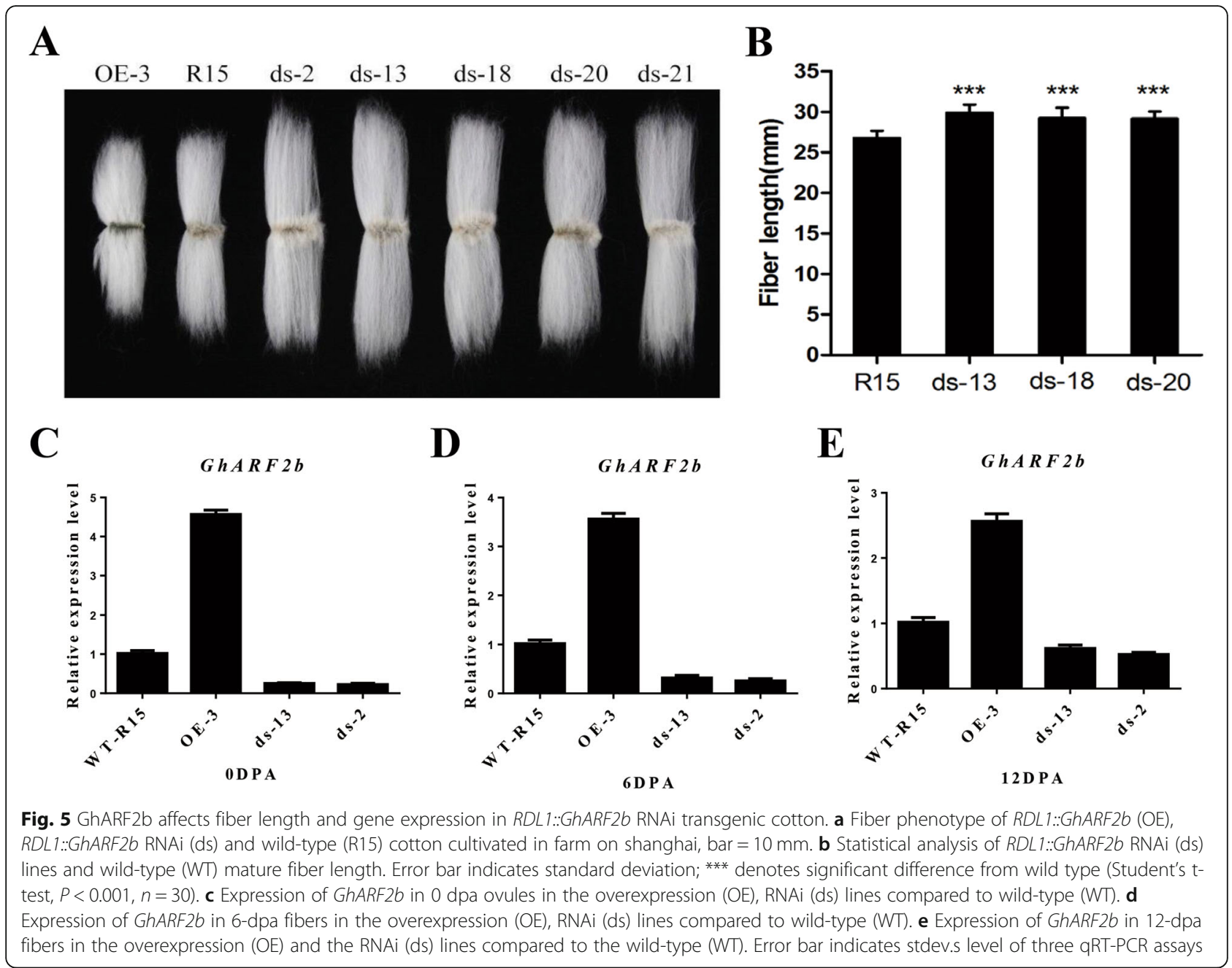

showed higher and lower densities of fiber initials compared to the wild-type control (Fig. 8). Further, we magnified the SEM views of ovules to 500-700× (Fig. 9). Obviously, at the fiber initiation stage (0, $1 \mathrm{DPA})$, the fiber initial density of the OE- 3 was increased by about 1.5 -fold compared with that of the wild-type, in contrast, the fiber initial density of the ds-2 line was reduced (Fig. 9a-c). These results support a role of GhARF2b in promoting cotton fiber cell initiation.

\section{Discussion}

Currently, more than 20 cotton genome sequences have been assembled and released, including diploid G. raimondii [37, 38], G. herbaceum and G. arboreum [39-41] and tetraploid G. hirsutum, G. barbadense, G. tomentosum, G. mustelinum and G. darwinii [41-49]. These genome sequences provided a platform for dissecting gene functions by forward and reverse genetics and would accelerate the rate of molecular breeding in cotton. Here, based on these high-quality genome sequences, we additionally characterized 36 ARF genes in G. arboreum and 73 in G. hirsutum, adding valuable data to understanding the distribution and evolution of ARF genes in cotton plants.

After whole genome duplication, the amplified genes generally undergo the events of functional loss, or neofunctionalization or subfunctionalization [50]. In this study, we found that six GhARF genes (five from $\mathrm{A}_{\mathrm{t}}$ subgenome) have experienced relatively faster positive selection compared to its diploid progenitors. Thus, duplicated genes from $A_{t}$ and $D_{t}$ subgenomes might be functionally diverged in the allotetraploid cotton after the merge of the two genomes. In addition, the GhARF genes expression profiles analyzed from the RNA-seq data showed subgenome-biased expression that might undergone functional divergence during the evolution. For instance, unequal expressions were observed in A and D-subgenome genes, including GhARF3c, GhARF16c, GhARF18a and GhARF20. These massive alterations in gene expression can cause distinct function and may just be one of the important features emerging 


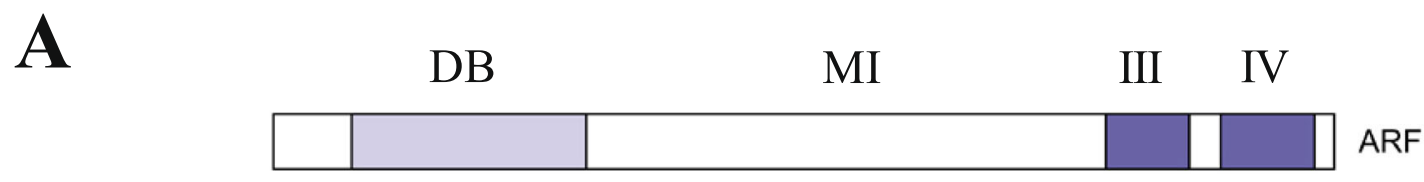

B

GhARF2b domain

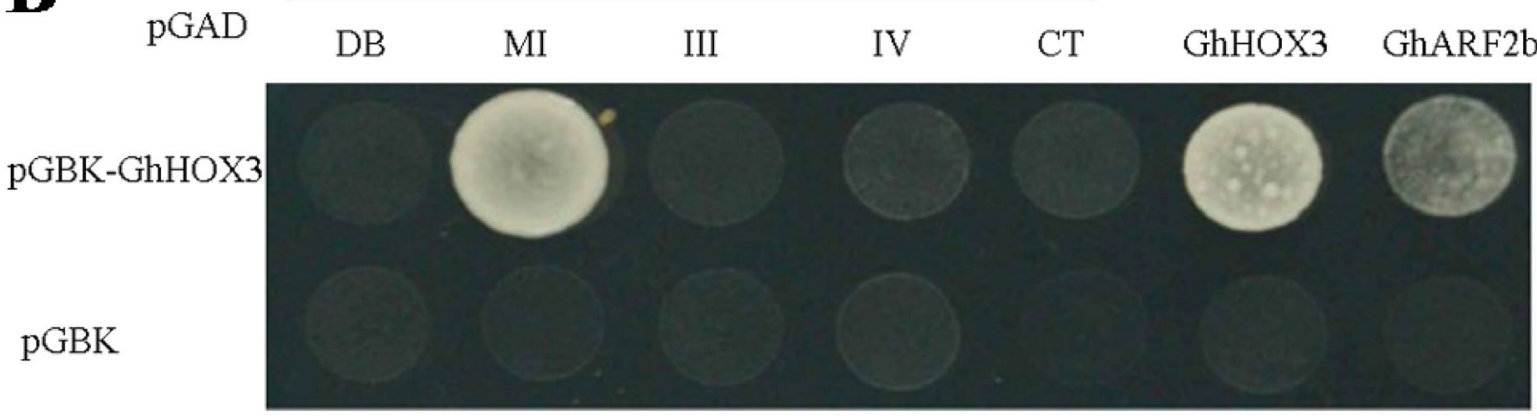

SD-L-T-H 5mM 3AT

$\mathbf{C}$
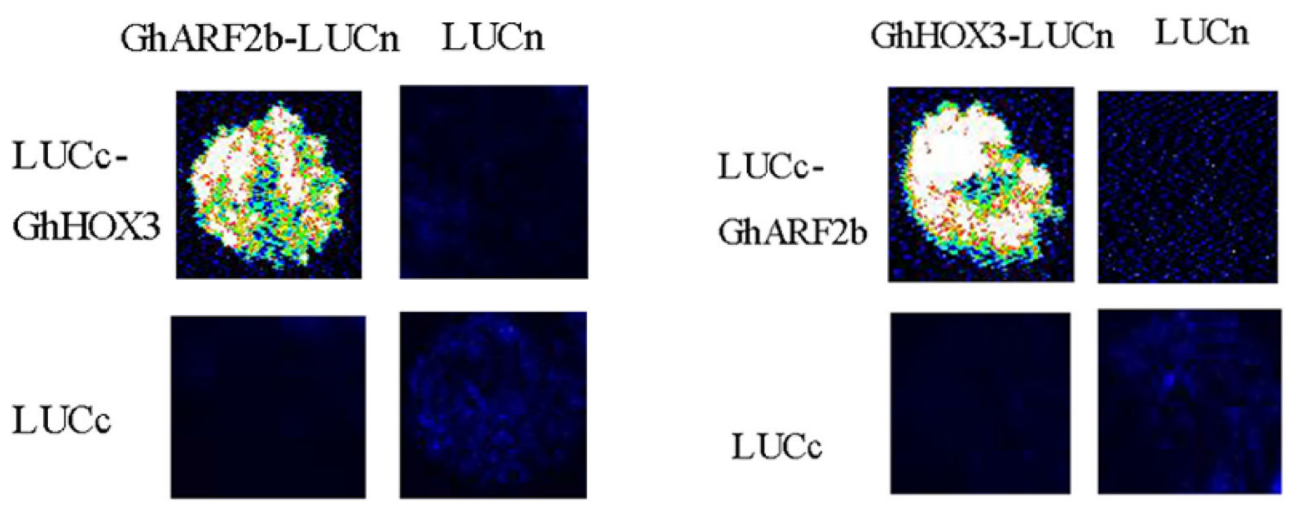

Fig. 6 Interaction of GhARF2b and GhHOX3. a Diagram of protein domains in ARF protein. $\mathbf{b}$ GhARF2b and GhARF2b middle region can interact with GhHOX3 in Y2H assay. The figure shows yeast grown on SD/-Leu-Trp-His with 5 mM 3AT (3-amino-1,2,4-triazole). c GhHOX3 and GhARF2b are interchangeably fused to the carboxyl- and amino-terminal of firefly luciferase (LUC, LUCC and LUCn), transiently co-expressed, and LUCC or LUCn was co-expressed with each other or with each unfused target protein as the control. Fluorescence signal intensities represent their binding activities

from polyploid $[8,51]$. During the evolution of allopolyploid, some duplicate gene pairs (homoeologs) are expressed unequally, as also proved in the allopolyploid cotton genome with the features of asymmetrical evolution [42]. The above results indicated that this suite of unequally expressed genes may be a fundamental feature of allopolyploids.

Previous studies showed that ARF family genes have been identified in many plant species, including 23 ARF genes in Arabidopsis thaliana [26], 25 in Oryza sativa [27], 39 in Populus trichocarpa [52], 31 in Zea mays [53], 15 in Cucumis sativus [54] and 35 in G. raimondii [32]. Auxin response factors (ARFs) are important in plant development as they play crucial roles in regulating a variety of signaling pathways [24, 25]. According to their functions, ARF proteins are divided into two classes: transcriptional activators and transcriptional repressors [24]. Many studies have revealed their regulatory roles in regulating various aspects of cellular activities $[35,55-57]$. As transcriptional repressors, ARF2 was involved in the regulation of $\mathrm{K}^{+}$uptake by repressing HAK5 transcription in Arabidopsis [34]. In addition, ARF2 is regulated by a variety of upstream factors at the transcription and protein levels, and participated in the pathways of auxin, gibberellin, oleoresin, ethylene and abscisic acid [28, 29, 31, 58]. 


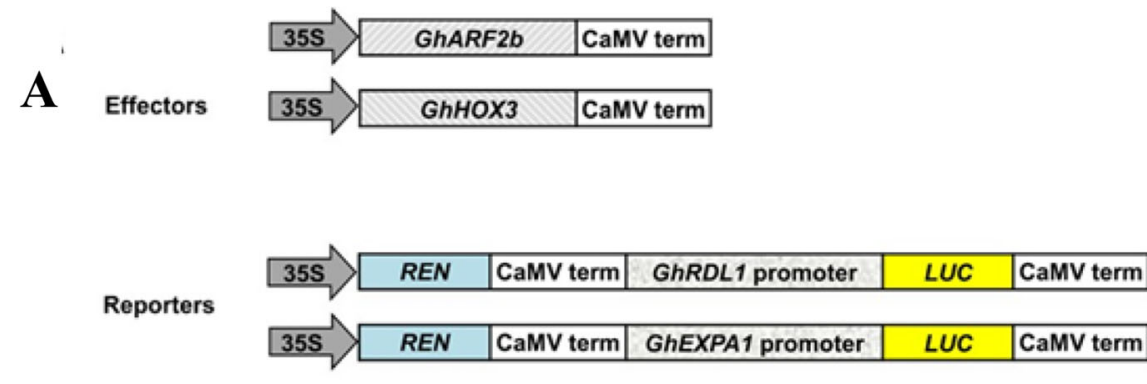

B

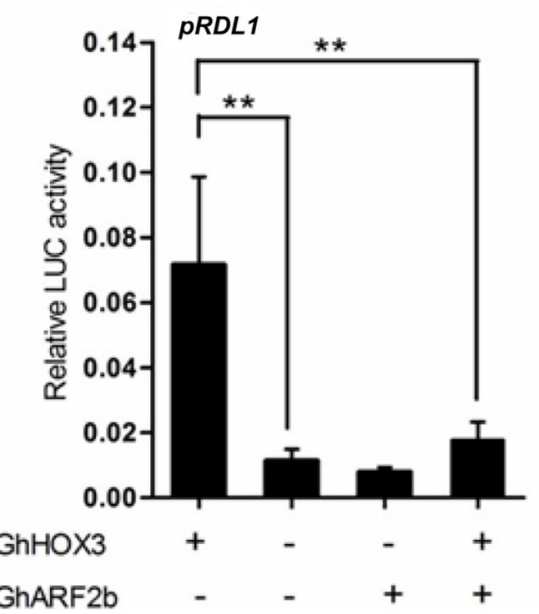

C

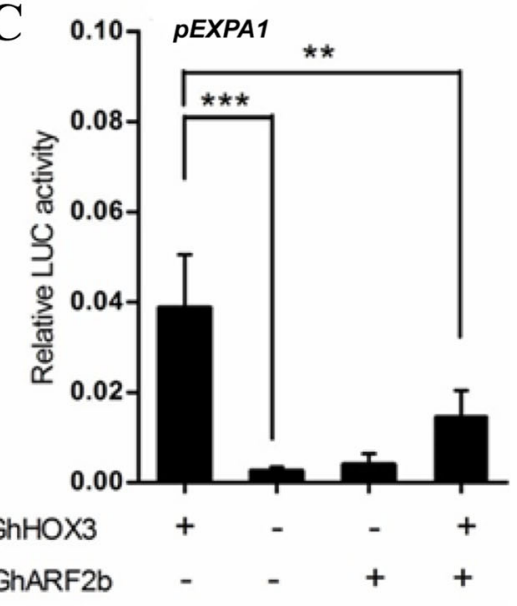

Fig. 7 GhARF2b represses the function of GhHOX3. a Diagram of vectors used in this assay. $\mathbf{b}$ GhARF2b affects the activation of GhHOX3 to GhRDL1. c GhARF2b affects the activation of GhHOX3 to GhEXPA1. Data are presented as mean \pm S.D., $n=3$, ${ }^{* *} P<0.01,{ }^{* * *} P<0.001$, Student's t-test)

In cotton, Zhang et al. uncovered that expression of the IAA biosynthetic gene, iaaM, can significantly increase IAA levels in the epidermis of cotton ovules at the fiber initiation stage, and increased the number of lint fibers and lint percentage in a 4-year field trial. They proved that the lint percentage of the transgenic cotton was increased in transgenic plants with a $15 \%$ increase in lint yield [59]. Han et al. found that the auxin response factor gene (GhARF3) was highly correlated with fibre quality by using the haplotype analysis and transcriptomic data. Above all, auxin signaling plays an essential role in regulating fibre development. In addition, Xiao et al. showed that G. hirsutum ARF genes promoted the trichome initiation in transgenic Arabidopsis plants [60]. They identified 56 GhARF genes in their study, including three GhARF2 genes [60]. They showed that GhARF2-1 could be exclusively expressed in trichomes, and overexpression of GhARF2-1 in Arabidopsis can enhance trichome initiation. But their study did not perform the cotton transformation to test the function of GhARF2-1 in cotton fiber cell.

\section{Conclusions}

In our study, we reported 73 GhARF genes in Gossypium hirsutum genome, including 9 GhARF2 genes. Among them, GhARF2b, was specifically higher expressed in developing fibers. Overexpression of GhARF2b represses fiber elongation, and RNAi silencing of GhARF2b promotes the fiber longer. Through yeast two-hybrid assays and the Dual-LUC experiment, GhARF2b plays a negative role in controlling cotton fiber elongation by interacting with GhHOX3. Further, GhARF2b was shown to promote the production of fiber initials, suggesting that auxin is an important player in controlling cotton fiber development. The auxin signaling pathways in developing cotton fiber cells deserve further investigation.

\section{Methods}

Identification of Gossypium species ARF factors

G. raimondii [37], G. arboreum [39], G. hirsutum [42] genome sequences were acquired from the CottonGen database [61]. We developed a Hidden Markov Model [62] profile matrix of ARF factors (Pfam ID: PF06507) 


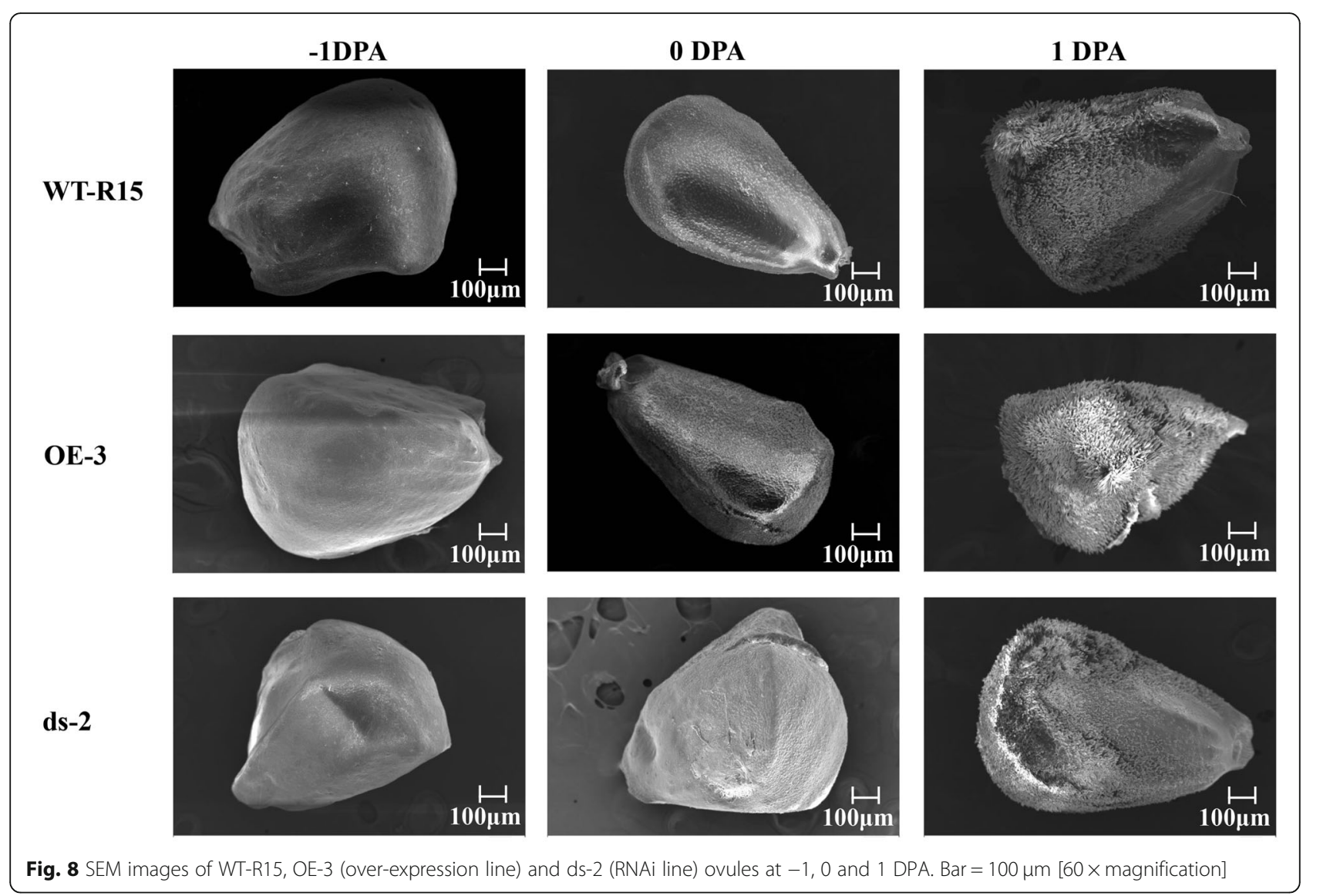

via the hmmbuild program [63] with default parameters to identify Gossypium ARF transcription factor proteins. SMART conserved domain search tool [64] and Pfam databases [65] were used to identify the conserved domain.

\section{Sequence alignment, Ka, Ks analyses and phylogenetic} analyses

Gossypium ARF factor amino acids and nucleotide sequences were aligned by MAFFT software with the GINS-i algorithm [66]. Ka, Ks and $\mathrm{Ka} / \mathrm{Ks}$ values for each gene pairs between diploid and allotetraploid were calculated by DnaSP v5 [67]. The Neighbor-Joining (NJ) phylogenetic tree was drawn by MEGA 5.03 [68] by sampling 1000 bootstrap replicates based on the ARF whole protein sequences.

\section{Gene expression analyses based on transcriptome}

Raw RNA-Seq data were downloaded from the NCBI Sequence Read Archive (https://www.ncbi.nlm.nih.gov/ bioproject/PRJNA248163) [42], including G. hirsutum seed, root, stem, leaf, torus, petal, stamen, ovary, calyx, ovule $(-3 \mathrm{dpa},-1 \mathrm{dpa}, 0 \mathrm{dpa}, 1 \mathrm{dpa}, 3 \mathrm{dpa}, 5 \mathrm{dpa}, 10$ dpa, $20 \mathrm{dpa}, 25 \mathrm{dpa}, 35 \mathrm{dpa})$ and fiber $(5 \mathrm{dpa}, 10 \mathrm{dpa}, 20$ dpa, 25dpa). The method of gene expression analyses based on transcriptome was same to our previous study [69]. Differentially expressed genes were determined based on the following criteria: more than two-fold change and $p$-value less than 0.05. Multiple Experiment Viewer $(\mathrm{MeV})$ [70] was used to display the gene expression values.

\section{Plant materials and growth conditions}

Gossypium hirsutum cv. R15 wild type plants were obtained from Institute of Cotton Research, Shanxi Academy of Agricultural Sciences, Yuncheng, Shanxi, China. Upland cotton R15 plants and its transgenic lines were grown in a greenhouse or in a field under standard farming conditions, which is in the experimental field of Chinese Academy of Sciences in Shanghai according to relevant national approvals for biotechnology research (China, http://pg.natesc.gov.cn/sites/pg/). The greenhouse is in a controlled environment at $28^{\circ} \mathrm{C}$ day $/ 20^{\circ} \mathrm{C}$ night, a 16-h light/8-h dark photoperiod. Cotton tissues, including roots, cotyledon, petal, stamen, style, ovules $(-3,-1,0$ and $6 \mathrm{dpa})$ and fiber $(3,6,12$ and $18 \mathrm{dpa})$ were collected for expression analyses. Fibers were collected by scraping the ovule in liquid nitrogen. All these tissues were frozen in liquid nitrogen immediately after 
A
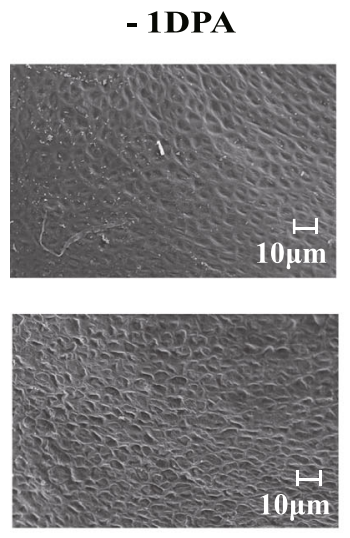

OE-3

WT-R15

ds-2

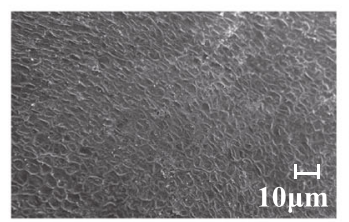

O DPA
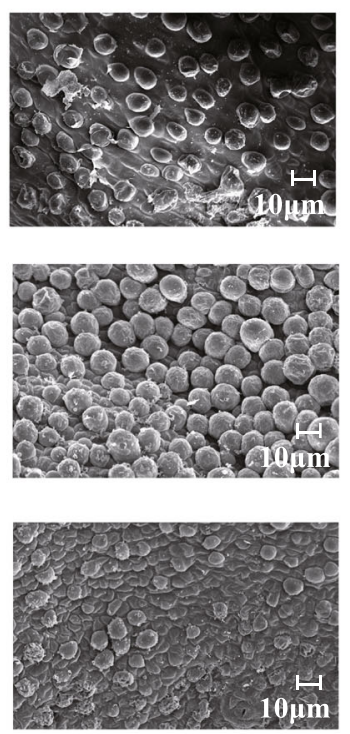

1 DPA
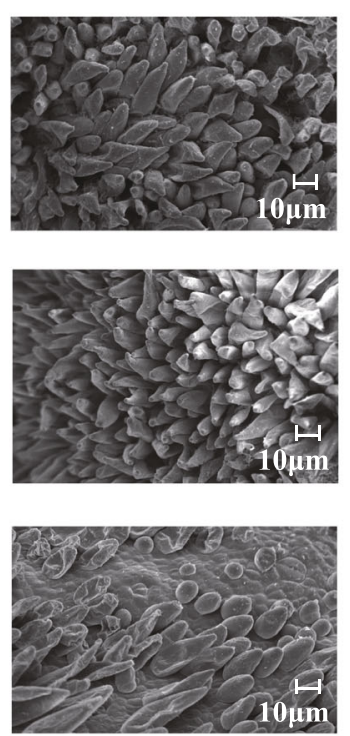

B

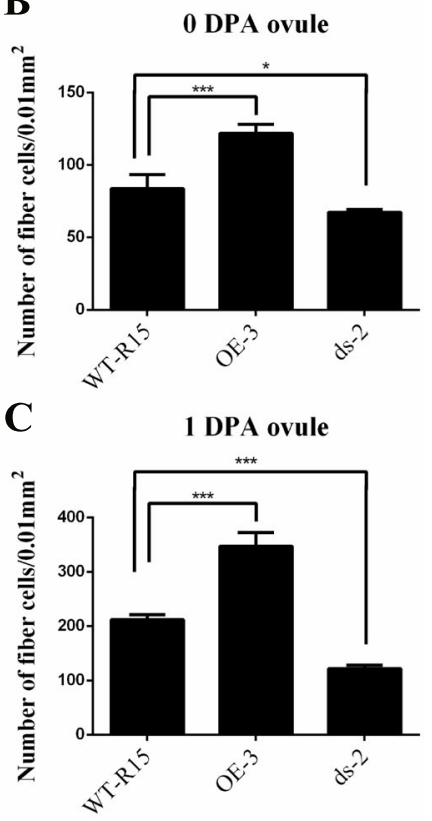

Fig. 9 GhARF2b enhances the fiber initiation. a SEM images of WT-R15, OE-3 (over-expression line) and ds-2 (RNAi line) ovules at - 1, 0, 1 DPA. Bar $=100 \mu \mathrm{m}$ [700 $\times$ magnification for ovules of -1 and 0 DPA, $500 \times$ magnification for 1-DPA ovules]. $\mathbf{b}$ Number of fiber cells per $0.01 \mathrm{~mm}^{2}$ of 0 DPA ovules in the overexpression (OE-3) and RNAi (ds-2) cotton lines compared to wild-type (WT-R15). Error bar indicates standard deviation; *** denotes significant difference from wild-type (Student's t-test, $P<0.001, n=30$ ); ${ }^{*}$ denotes significant difference from wild type (Student's t-test, $P<0.05, n=30$ ). c Number of fiber cells per $0.01 \mathrm{~mm}^{2}$ of 1-DPA ovules in the overexpression (OE-3) and RNAi (ds-2) cotton lines compared to wild-type (WT-R15). Error bar indicates standard deviation; ${ }^{* *}$ denotes significant difference from wild type (Student's t-test, $P<0.001, n=30$ )

sampling and stored at $-80^{\circ} \mathrm{C}$ until RNA extraction. Three times were repeated for all these treatments.

\section{qRT-PCR analyses}

All cotton samples were ground in liquid nitrogen and total RNAs of these cotton tissues were extracted using the RNAprep pure plant kit (TIANGEN, Shanghai, China) following the manufacturer's protocol. The method of qRT-PCR analyses was same to our previous study [69]. The forward and reverse primers of specific gene for quantitative real-time PCR (qRT-PCR) analyses, were designed using the Primer5 software (Additional file 3: Table S1). Analyses were performed with SYBR-Green PCR Mastermix (TaKaRa) on a cycler (Mastercycler RealPlex; Eppendorf Ltd., Shanghai, China). The internal gene was G. hirsutum histone-3 (GhHIS3, AF024716), and the 2- $\Delta \Delta \mathrm{Ct}$ method was used to calculate the relative amount of amplified product [71]. Relative expression levels among different organs of G. hirsutum samples were normalized by calibrating with the WT samples.

\section{Cotton transformation and fiber length analysis}

The open reading frame (ORF) of GhARF2b was PCRamplified from a G. hirsutum cv R15 fiber cDNA library with PrimeSTAR HS DNA polymerase (Takara
Biomedical Technology Co. Ltd., Beijing, China) and inserted into the $p C A M B I A 2301$ vector to construct RDL1::GhARF2b. For 35S::dsGhARF2b, sense and antisense: GhARF2b fragments, separated by a 120-bp intron of the RTM1 gene from $A$. thaliana, were cloned into $p C A M B I A 2301$. Primers used in this investigation are listed in Additional file 3: Table S1. The binary constructs were transferred into Agrobacterium tumefaciens. Cotton transformation was conducted as reported in Shangguan et al. [72]. Transgenic cotton plants were grown in glasshouse or field. $\beta$-glucuronidase (GUS) staining and PCR amplification were performed to identify the transgenic lines of $\mathrm{T}_{0}$ and subsequent generations. Thirty seeds from each plant were harvested to statistics fiber length.

\section{Yeast two-hybrid assay}

Yeast two-hybrid analysis were carried out using the Matchmaker GAL4 Two-Hybrid System as performed previously [5]. Briefly, for the yeast two-hybrid assays, the full-length ORF of GhHOX3 inserted into pGBKT7 (Clontech) and GhARF2b or GhARF2b different domains into pGADT7 (Clontech). Plasmids were cotransferred into yeast strain AH109 by the LiCl-PEG method, and SD/-Leu/-Trp/-His selective plates containing 5 mM 3-AT (3-amino-1,2,4,-triazole) were used 
to detect the protein-protein interactions. pGADT7 and pGBKT7 empty vectors were used as controls. Three biological duplications for each transformation were performed.

\section{BiFC and dual-luciferase (dual-LUC) assays}

We performed the BiFC assays following previous reports [73, 74]. In summary, CDSs of GhARF2b and GhHOX3 were amplified and cloned into JW771 and JW772 vectors, respectively. Each gene was fused to the carboxyl-terminal half (cLUC-GhARF2b/GhHOX3) and the amino-terminal half (GhARF2b/GhHOX3-nLUC) of luciferase (LUC), respectively. cLUC and nLUC were used as controls. Assays were finished as described $[5,75]$.

The Dual-LUC assay was performed as reported [5, 76]. Briefly, the promoters containing intact L1-boxes of GhRDL1 and GhEXPA1 were inserted into pGreen-LUC vector with a firefly LUC reporter gene. Then, the constructs were transferred into Agrobacterium tumefaciens cell with a co-suppression repressor plasmid pSoup-P19. Transient transformation was conducted by infiltrating the $A$. tumefaciens cells into $N$. benthamiana leaves. The total protein was extracted from the infected area after 3 days. The Dual-Luciferase Reporter Assay System (Promega) was used to detect the fluorescent values of LUC and REN with a luminometer (BG-1, GEM Biomedical Inc.). The value of LUC was normalized to that of REN. Three biological replicates were measured for each experiment.

\section{Microscope observation}

Images were generated with an optical microscope (BX51, Olympus). For scanning electron microscope images, cotton ovules $(-1,0,1 \mathrm{DPA})$ were attached with colloidal graphite to a copper stub, frozen under vacuum and visualized with a scanning electron microscope (JSM-6360LV, JEOL).

\section{Abbreviations}

ARFs: Auxin response factors; Dpa: Days post anthesis; FPKM: Fragments per kilobase of transcript per million mapped fragments; G. arboreum: Gossypium arboreum; G. hirsutum: Gossypium hirsutum; G. raimondii: Gossypium raimondii; WT: wild type; OE: Overexpression; ds: RNAi; qRT-PCR: Quantitative real-time polymerase chain reaction

\section{Supplementary Information}

The online version contains supplementary material available at https://doi. org/10.1186/s12864-021-07504-6.

Additional file 1: Figure S1. Multiple alignment of GrARF2 (Gossypium raimondii ARF2) and AtARF2 protein sequences.

Additional file 2: Figure S2. Expression patterns of ARF genes in G. hirsutum based on RNA-seq data. FPKM represents fragments per kilobase of exon model per million mapped reads. DPA, days post-anthesis.s.

Additional file 3: Table S1. List of forward and reverse primers used for this study.

\section{Acknowledgements}

We thank Prof. Tian-Zhen Zhang for providing the RNA-seq data and calculating the RPKM values and Prof. Xiao-Ya Chen participating in discussion and revising the manuscript.

\section{Authors' contributions}

ZWC, XFZ and LJW designed the research. ZWC, XFZ, JFC, CCH, XL and YGZ performed the experiments. XFZ, ZSZ, XXSG, LJW and ZWC contributed materials and analyzed data. ZWC wrote and revised the manuscript. All the authors read and approved the final version of the manuscript.

\section{Funding}

This work reported in this publication was supported by the National Natural Science Foundation of China through the Awards Nos. 31690092, 31571251, 31788103, the National Key R\&D Program of China (2016YFD0100500) and the Ministry of Agriculture of China (2016ZX08005-003), the China Postdoctoral Science Foundation through the Awards Nos. 2017 M621546 and 2018 T110411. The funding bodies did not participate in the design of the study and collection, analysis, and interpretation of data and in writing the manuscript.

\section{Availability of data and materials}

The genome sequences of three cotton species and the genome annotation gff3 file were downloaded from the CottonGen database (https://www. cottongen.org/data/download) [59]. Raw RNA-Seq data for G. hirsutum seed, root, stem, leaf, torus, petal, stamen, ovary, calyx, ovule and fiber were downloaded from the NCBI Sequence Read Archive (https://www.ncbi.nlm.nih. gov/bioproject/PRJNA248163) (NCBI Sequence Read Archive SRR1695173, SRR1695174, SRR1695175, SRR1695177, SRR1695178, SRR1695179, SRR1695181, SRR1695182, SRR1695183, SRR1695184, SRR1695185, SRR1695191, SRR1695192, SRR1695193,SRR1695194, SRR1768504, SRR1768505, SRR1768506, SRR1768507, SRR1768508, SRR1768509, SRR1768510, SRR1768511, SRR1768512, SRR1768513, SRR1768514, SRR1768515, SRR1768516, SRR1768517, SRR1768518 and SRR1768519) [30]. The G. hirsutum histone-3 (GhHIS3, AF024716) gene was downloaded from the National Center for Biotechnology Information (NCBI) database, which were used as internal references. The conserved domain of ARF transcription factors (Pfam ID: PF06507) was downloaded from the Pfam databases (http://pfam.xfam. org/family/PF06507\#tabview=tab3). All other data generated or analyzed during this study are included in this published article and its Additional files.

\section{Declarations}

Ethics approval and consent to participate

Not applicable.

\section{Consent for publication}

Not applicable.

\section{Competing interests}

The authors declare that they have no competing interests.

\section{Author details}

${ }^{1}$ National Key Laboratory of Plant Molecular Genetics and National Center for Plant Gene Research, Institute of Plant Physiology and Ecology/CAS Center for Excellence in Molecular Plant Sciences, Chinese Academy of Sciences, Shanghai 200032, China. ${ }^{2}$ Plant Stress Biology Center, Institute of Plant Physiology and Ecology/CAS Center for Excellence in Molecular Plant Sciences, Chinese Academy of Sciences, Shanghai 200032, China. ${ }^{3}$ University of Chinese Academy of Sciences, Shanghai 200032, China. ${ }^{4}$ School of Life Science and Technology, ShanghaiTech University, Shanghai 201210, China. ${ }^{5}$ Esquel Group, 25 Harbour Road, Wanchai, Hong Kong, China. ${ }^{6}$ Institute of Carbon Materials Science, Shanxi Datong University, Datong 037009, China.

Received: 16 November 2020 Accepted: 2 March 2021

Published online: 22 March 2021

\section{References}

1. Schell J. Cotton carrying the recombinant insect poison Bt toxin: no case to doubt the benefits of plant biotechnology. Curr Opin Biotechnol. 1997;8(2): 235-6. 
2. Kim HJ, Triplett BA. Cotton fiber growth in planta and in vitro. Models for plant cell elongation and cell wall biogenesis. Plant Physiol. 2001;127(4): 1361-6.

3. Graves DA, Stewart JM. Chronology of the differentiation of cotton (Gossypium hirsutum L.) fiber cells. Planta. 1988;175(2):254-8.

4. Fang DD, Naoumkina M, Kim HJ. Unraveling cotton Fiber development using Fiber mutants in the post-genomic era. Crop Sci. 2018;58(6):2214-28

5. Shan CM, Shangguan XX, Zhao B, Zhang XF, Chao LM, Yang CQ, Wang L, Zhu HY, Zeng YD, Guo WZ, et al. Control of cotton fibre elongation by a homeodomain transcription factor GhHOX3. Nat Commun. 2014;5:5519.

6. Guan XY, Li QJ, Shan CM, Wang S, Mao YB, Wang LJ, Chen XY. The HD-zip IV gene GaHOX1 from cotton is a functional homologue of the Arabidopsis GLABRA2. Physiol Plant. 2008;134(1):174-82.

7. Walford SA, Wu Y, Llewellyn DJ, Dennis ES. Epidermal cell differentiation in cotton mediated by the homeodomain leucine zipper gene, GhHD-1. Plant J. 2012;71(3):464-78

8. Zhao B, Cao JF, Hu GJ, Chen ZW, Wang LY, Shangguan XX, Wang LJ, Mao YB, Zhang TZ, Wendel JF, et al. Core cis-element variation confers subgenome-biased expression of a transcription factor that functions in cotton fiber elongation. New Phytol. 2018;218(3):1061-75.

9. Gong SY, Huang GQ, Sun X, Qin LX, Li Y, Zhou L, Li XB. Cotton KNL1, encoding a class II KNOX transcription factor, is involved in regulation of fibre development. J Exp Bot. 2014;65(15):4133-47.

10. Zhang Z, Ruan YL, Zhou N, Wang F, Guan X, Fang L, Shang X, Guo W, Zhu $S$, Zhang T. Suppressing a putative sterol carrier gene reduces Plasmodesmal permeability and activates sucrose transporter genes during cotton Fiber elongation. Plant Cell. 2017;29(8):2027-46.

11. Wan Q, Guan X, Yang N, Wu H, Pan M, Liu B, Fang L, Yang S, Hu Y, Ye W, et al. Small interfering RNAs from bidirectional transcripts of GhMML3_A12 regulate cotton fiber development. New Phytol. 2016;210(4):1298-310.

12. Wu H, Tian Y, Wan Q, Fang L, Guan X, Chen J, Hu Y, Ye W, Zhang H, Guo W, et al. Genetics and evolution of MIXTA genes regulating cotton lint fiber development. New Phytol. 2018;217(2):883-95.

13. Machado A, Wu Y, Yang Y, Llewellyn DJ, Dennis ES. The MYB transcription factor GhMYB25 regulates early fibre and trichome development. Plant J. 2009;59(1):52-62.

14. Walford SA, Wu Y, Llewellyn DJ, Dennis ES. GhMYB25-like: a key factor in early cotton fibre development. Plant J. 2011;65(5):785-97.

15. Zhang J, Huang GQ, Zou D, Yan JQ, Li Y, Hu S, Li XB. The cotton (Gossypium hirsutum) NAC transcription factor (FSN1) as a positive regulator participates in controlling secondary cell wall biosynthesis and modification of fibers. New Phytol. 2018;217(2):625-40.

16. Han LB, Li YB, Wang HY, Wu XM, Li CL, Luo M, Wu SJ, Kong ZS, Pei Y, Jiao $G L$, et al. The dual functions of WLIM1a in cell elongation and secondary wall formation in developing cotton fibers. Plant Cell. 2013;25(11): 4421-38.

17. Ruan YL, Llewellyn DJ, Furbank RT. Suppression of sucrose synthase gene expression represses cotton fiber cell initiation, elongation, and seed development. Plant Cell. 2003;15(4):952-64.

18. Li XB, Fan XP, Wang XL, Cai L, Yang WC. The cotton ACTIN1 gene is functionally expressed in fibers and participates in fiber elongation. Plant Cell. 2005;17(3):859-75.

19. Xu B, Gou JY, Li FG, Shangguan XX, Zhao B, Yang CQ, Wang LJ, Yuan S, Liu $\mathrm{CJ}$, Chen XY. A cotton BURP domain protein interacts with alpha-expansin and their co-expression promotes plant growth and fruit production. Mol Plant. 2013;6(3):945-58

20. Shi YH, Zhu SW, Mao XZ, Feng JX, Qin YM, Zhang L, Cheng J, Wei LP, Wang ZY, Zhu YX. Transcriptome profiling, molecular biological, and physiological studies reveal a major role for ethylene in cotton fiber cell elongation. Plant Cell. 2006;18(3):651-64

21. Huang GQ, Gong SY, Xu WL, Li W, Li P, Zhang CJ, Li DD, Zheng Y, Li FG, Li XB. A fasciclin-like arabinogalactan protein, GhFLA1, is involved in fiber initiation and elongation of cotton. Plant Physiol. 2013;161(3):1278-90.

22. Cao JF, Zhao B, Huang CC, Chen ZW, Zhao T, Liu HR, Hu GJ, Shangguan XX, Shan CM, Wang LJ, et al. The miR319-targeted GhTCP4 promotes the transition from cell elongation to wall thickening in cotton fiber. Mol Plant. 2020;13(7):1063-77.

23. Yu Y, Wu S, Nowak J, Wang G, Han L, Feng Z, Mendrinna A, Ma Y, Wang H, Zhang $X$, et al. Live-cell imaging of the cytoskeleton in elongating cotton fibres. Nat Plants. 2019;5(5):498-504.
24. Guilfoyle TJ, Hagen G. Auxin response factors. Curr Opin Plant Biol. 2007; 10(5):453-60.

25. Tiwari SB, Hagen G, Guilfoyle $T$. The roles of auxin response factor domains in auxin-responsive transcription. Plant Cell. 2003;15(2):533-43.

26. Okushima Y, Overvoorde PJ, Arima K, Alonso JM, Chan A, Chang C, Ecker JR, Hughes B, Lui A, Nguyen D, et al. Functional genomic analysis of the AUXIN RESPONSE FACTOR gene family members in Arabidopsis thaliana: unique and overlapping functions of ARF7 and ARF19. Plant Cell. 2005;17(2):444-63.

27. Wang DK, Pei KM, Fu YP, Sun ZX, Li SJ, Liu HQ, Tang K, Han B, Tao YZ. Genome-wide analysis of the auxin response factors (ARF) gene family in rice (Oryza sativa). Gene. 2007;394(1-2):13-24.

28. Vert $\mathrm{G}$, Walcher $\mathrm{CL}$, Chory J, Nemhauser JL. Integration of auxin and brassinosteroid pathways by Auxin response factor 2. Proc Natl Acad Sci U S A. 2008;105(28):9829-34.

29. Wang L, Hua DP, He JN, Duan Y, Chen ZZ, Hong XH, Gong ZZ. Auxin response factor2 (ARF2) and its regulated homeodomain gene hb33 mediate abscisic acid response in arabidopsis. PLoS Genet. 2011;7(7): e1002172.

30. Schruff MC, Spielman M, Tiwari S, Adams S, Fenby N, Scott RJ. The AUXIN RESPONSE FACTOR 2 gene of Arabidopsis links auxin signalling, cell division, and the size of seeds and other organs. Development. 2006;133(2):251-61.

31. Breitel DA, Chappell-Maor L, Meir S, Panizel I, Puig CP, Hao Y, Yifhar T, Yasuor $\mathrm{H}$, Zouine $\mathrm{M}$, Bouzayen $\mathrm{M}$, et al. AUXIN RESPONSE FACTOR 2 intersects hormonal signals in the regulation of tomato fruit ripening. PLOS Genet. 2016;12(3):e1005903.

32. Sun RR, Wang KB, Guo TL, Jones DC, Cobb J, Zhang BH, Wang QL. Genomewide identification of auxin response factor (ARF) genes and its tissuespecific prominent expression in Gossypium raimondii. Function Integr Genom. 2015:15(4):481-93.

33. Lim PO, Lee IC, Kim J, Kim HJ, Ryu JS, Woo HR, Nam HG. Auxin response factor 2 (ARF2) plays a major role in regulating auxin-mediated leaf longevity. J Exp Bot. 2010;61(5):1419-30.

34. Zhao S, Zhang ML, Ma TL, Wang Y. Phosphorylation of ARF2 relieves its repression of transcription of the $\mathrm{K}+$ transporter gene HAK5 in response to low potassium stress. Plant Cell. 2016;28(12):3005-19.

35. Okushima Y, Mitina I, Quach HL, Theologis A. AUXIN RESPONSE FACTOR 2 (ARF2): a pleiotropic developmental regulator. Plant J Cell Mol Biol. 2005; 43(1):29-46.

36. Wang S, Wang JW, Yu N, Li CH, Luo B, Gou JY, Wang LJ, Chen XY. Control of plant trichome development by a cotton fiber MYB gene. Plant Cell. 2004;16(9):2323-34.

37. Paterson AH, Wendel JF, Gundlach $H$, Guo H, Jenkins J, Jin D, Llewellyn D, Showmaker KC, Shu S, Udall J, et al. Repeated polyploidization of Gossypium genomes and the evolution of spinnable cotton fibres. Nature. 2012;492(7429):423-7

38. Wang K, Wang Z, Li F, Ye W, Wang J, Song G, Yue Z, Cong L, Shang H, Zhu $S$, et al. The draft genome of a diploid cotton Gossypium raimondii. Nat Genet. 2012;44(10):1098-103.

39. Li F, Fan G, Wang K, Sun F, Yuan Y, Song G, Li Q, Ma Z, Lu C, Zou C, et al. Genome sequence of the cultivated cotton Gossypium arboreum. Nat Genet. 2014:46(6):567-72.

40. Du X, Huang G, He S, Yang Z, Sun G, Ma X, Li N, Zhang X, Sun J, Liu M, et al. Resequencing of 243 diploid cotton accessions based on an updated a genome identifies the genetic basis of key agronomic traits. Nat Genet. 2018:50(6):796-802.

41. Huang G, Wu Z, Percy RG, Bai M, Li Y, Frelichowski JE, Hu J, Wang K, Yu JZ, Zhu Y. Genome sequence of Gossypium herbaceum and genome updates of Gossypium arboreum and Gossypium hirsutum provide insights into cotton A-genome evolution. Nat Genet. 2020;52(5):516-24.

42. Zhang T, Hu Y, Jiang W, Fang L, Guan X, Chen J, Zhang J, Saski CA, Scheffler $B E$, Stelly DM, et al. Sequencing of allotetraploid cotton (Gossypium hirsutum L. acc. TM-1) provides a resource for fiber improvement. Nat Biotechnol. 2015;33(5):531-7.

43. Chen ZJ, Sreedasyam A, Ando A, Song Q, De Santiago LM, Hulse-Kemp AM, Ding M, Ye W, Kirkbride RC, Jenkins J, et al. Genomic diversifications of five Gossypium allopolyploid species and their impact on cotton improvement. Nat Genet. 2020;52(5):525-33

44. Li F, Fan G, Lu C, Xiao G, Zou C, Kohel RJ, Ma Z, Shang H, Ma X, Wu J, et al. Genome sequence of cultivated upland cotton (Gossypium hirsutum TM-1) provides insights into genome evolution. Nat Biotechnol. 2015;33(5):524-30 
45. Liu X, Zhao B, Zheng HJ, Hu Y, Lu G, Yang CQ, Chen JD, Chen JJ, Chen DY, Zhang $L$, et al. Gossypium barbadense genome sequence provides insight into the evolution of extra-long staple fiber and specialized metabolites. Sci Rep. 2015;5:14139.

46. Yuan D, Tang Z, Wang M, Gao W, Tu L, Jin X, Chen L, He Y, Zhang L, Zhu L, et al. The genome sequence of Sea-Island cotton (Gossypium barbadense) provides insights into the allopolyploidization and development of superior spinnable fibres. Sci Rep. 2015;5:17662.

47. Wang M, Tu L, Yuan D, Zhu D, Shen C, Li J, Liu F, Pei L, Wang P, Zhao $\mathrm{G}$, et al. Reference genome sequences of two cultivated allotetraploid cottons, Gossypium hirsutum and Gossypium barbadense. Nat Genet. 2019;51(2):224-9.

48. Hu Y, Chen J, Fang L, Zhang Z, Ma W, Niu Y, Ju L, Deng J, Zhao T, Lian J, et al. Gossypium barbadense and Gossypium hirsutum genomes provide insights into the origin and evolution of allotetraploid cotton. Nat Genet. 2019:51(4):739-48.

49. Yang Z, Ge X, Yang Z, Qin W, Sun G, Wang Z, Li Z, Liu J, Wu J, Wang Y, et al. Extensive intraspecific gene order and gene structural variations in upland cotton cultivars. Nat Commun. 2019;10(1):2989.

50. Wendel JF. The wondrous cycles of polyploidy in plants. Am J Bot. 2015; 102(11):1753-6.

51. Chen ZW, Cao JF, Zhang XF, Shangguan XX, Mao YB, Wang LJ, Chen XY. Cotton genome: challenge into the polyploidy. Sci Bull. 2017;62(24):1622-3.

52. Kalluri UC, Difazio SP, Brunner AM, Tuskan GA. Genome-wide analysis of auX/ IAA and ARF gene families in Populus trichocarpa. BMC Plant Biol. 2007;7:59.

53. Xing H, Pudake RN, Guo G, Xing G, Hu Z, Zhang Y, Sun Q, Ni Z. Genomewide identification and expression profiling of auxin response factor (ARF) gene family in maize. BMC Genomics. 2011;12(1):178.

54. Liu SQ, Hu LF. Genome-wide analysis of the auxin response factor gene family in cucumber. Genet Mol Res. 2013;12(4):4317-31.

55. Hardtke CS, Berleth T. The Arabidopsis gene MONOPTEROS encodes a transcription factor mediating embryo axis formation and vascular development. EMBO J. 1998;17(5):1405-11.

56. Nemhauser JL, Feldman LJ, Zambryski PC. Auxin and ETTIN in Arabidopsis gynoecium morphogenesis. Development. 2000;127(18):3877-88.

57. Ellis CM, Nagpal P, Young JC, Hagen G, Guilfoyle TJ, Reed JW. AUXIN RESPONSE FACTOR1 and AUXIN RESPONSE FACTOR2 regulate senescence and floral organ abscission in Arabidopsis thaliana. Development. 2005; 132(20):4563-74.

58. Richter R, Behringer C, Zourelidou M, Schwechheimer C. Convergence of auxin and gibberellin signaling on the regulation of the GATA transcription factors GNC and GNL in Arabidopsis thaliana. Proc Natl Acad Sci U S A. 2013;110(32):13192-7.

59. Zhang $M$, Zheng $X$, Song $S$, Zeng Q, Hou L, Li D, Zhao J, Wei Y, Li X, Luo $M$, et al. Spatiotemporal manipulation of auxin biosynthesis in cotton ovule epidermal cells enhances fiber yield and quality. Nat Biotechnol. 2011;29(5):453-8.

60. Xiao G, He P, Zhao P, Liu H, Zhang L, Pang C, Yu J. Genome-wide identification of the GhARF gene family reveals that GhARF2 and GhARF18 are involved in cotton fibre cell initiation. J Exp Bot. 2018;69(18):4323-37.

61. Yu J, Jung S, Cheng CH, Ficklin SP, Lee T, Zheng P, Jones D, Percy RG, Main D. CottonGen: a genomics, genetics and breeding database for cotton research. Nucleic Acids Res. 2014;42(Database issue):1229-36.

62. Wong DC, Schlechter R, Vannozzi A, Holl J, Hmmam I, Bogs J, Tornielli GB, Castellarin SD, Matus JT. A systems-oriented analysis of the grapevine R2R3MYB transcription factor family uncovers new insights into the regulation of stilbene accumulation. DNA Res. 2016;23:451-66.

63. Mistry J, Finn RD, Eddy SR, Bateman A, Punta M. Challenges in homology search: HMMER3 and convergent evolution of coiled-coil regions. Nucleic Acids Res. 2013;41(12):e121.

64. Letunic I, Bork P. 20 years of the SMART protein domain annotation resource. Nucleic Acids Res. 2018;46(D1):D493-6.

65. Finn RD, Coggill P, Eberhardt RY, Eddy SR, Mistry J, Mitchell AL, Potter SC, Punta M, Qureshi M, Sangrador-Vegas A, et al. The Pfam protein families database: towards a more sustainable future. Nucleic Acids Res. 2016;44(D1): D279-85.

66. Katoh K, Standley DM. MAFFT multiple sequence alignment software version 7: improvements in performance and usability. Mol Biol Evol. 2013; 30(4):772.

67. Librado P, Rozas J. DnaSP v5: a software for comprehensive analysis of DNA polymorphism data. Bioinformatics. 2009;25(11):1451-2.
68. Tamura K, Peterson D, Peterson N, Stecher G, Nei M, Kumar S. MEGA5 molecular evolutionary genetics analysis using maximum likelihood, evolutionary distance, and maximum parsimony methods. Mol Biol Evol. 2011;28(10):2731-9.

69. Cao J-F, Huang J-Q, Liu X, Huang C-C, Zheng Z-S, Zhang X-F, Shangguan X$X$, Wang L-J, Zhang Y-G, Wendel JF, et al. Genome-wide characterization of the GRF family and their roles in response to salt stress in Gossypium. BMC Genomics. 2020;21(1):575.

70. Saeed Al, Sharov V, White J, Li J, Liang W, Bhagabati N, Braisted J, Klapa M, Currier T, Thiagarajan M, et al. TM4: a free, open-source system for microarray data management and analysis. Biotechniques. 2003;34(2):374-8.

71. Livak KJ, Schmittgen TD. Analysis of relative gene expression data using real-time quantitative PCR and the 2(T) (-Delta Delta C) method. Methods. 2001;25(4):402-8.

72. Shangguan $X X, X u B, Y u Z X$, Wang $L$, Chen XY. Promoter of a cotton fibre MYB gene functional in trichomes of Arabidopsis and glandular trichomes of tobacco. J Exp Bot. 2008;59(13):3533-42.

73. Gou JY, Felippes FF, Liu CJ, Weigel D, Wang JW. Negative regulation of anthocyanin biosynthesis in Arabidopsis by a miR156-targeted SPL transcription factor. Plant Cell. 2011;23(4):1512-22.

74. Chen HM, Zou Y, Shang YL, Lin HQ, Wang YJ, Cai R, Tang XY, Zhou JM. Firefly luciferase complementation imaging assay for protein-protein interactions in plants. Plant Physiol. 2008;146(2):368-76.

75. Papp I, Mette MF, Aufsatz W, Daxinger L, Schauer SE, Ray A, van der Winden J, Matzke M, Matzke AJ. Evidence for nuclear processing of plant micro RNA and short interfering RNA precursors. Plant Physiol. 2003;132(3):1382-90.

76. Liu H, Yu X, Li K, Klejnot J, Yang H, Lisiero D, Lin C. Photoexcited CRY2 interacts with $\mathrm{CIB1}$ to regulate transcription and floral initiation in Arabidopsis. Science. 2008;322(5907):1535-9.

\section{Publisher's Note}

Springer Nature remains neutral with regard to jurisdictional claims in published maps and institutional affiliations.
Ready to submit your research? Choose BMC and benefit from:

- fast, convenient online submission

- thorough peer review by experienced researchers in your field

- rapid publication on acceptance

- support for research data, including large and complex data types

- gold Open Access which fosters wider collaboration and increased citations

- maximum visibility for your research: over $100 \mathrm{M}$ website views per year

At $\mathrm{BMC}$, research is always in progress.

Learn more biomedcentral.com/submissions 